\title{
Supermediastinoscopies: where to fit and how to do on cancer practice
}

\author{
Iury Andradade Melo, Gustavo Fortunato, Sergio Tadeu Lima Fortunato Pereira \\ CIRTORAX, Thoracic Surgery Clinic, Salvador, Bahia, Brazil \\ Correspondence to: Iury Andradade Melo. Thoracic surgeon, CIRTORAX, Thoracic Surgery Clinic, Salvador, Bahia, Brazil. \\ Email: iurymelo@cirtoraxbahia.com.br.
}

\begin{abstract}
For years cervical mediastinoscopy was the main and only way to access the mediastinal status on lung cancer, but on the last decade new technologies had evolved either imaging, endoscopic or surgical procedures. Each one can give you very good results, but still have a different degree of certainty detecting anatomical extent of disease. Based on some published data and on our experience, we will address the use of video-assisted mediastinal lymphadenectomy (VAMLA) and trans-cervical extended maximal lymphadenectomy (TEMLA), named by Dr. Rami Porta as supermediastinoscopies, show procedures differences and where do we fit them on our practice.
\end{abstract}

Keywords: Video-assisted mediastinal lymphadenectomy (VAMLA); trans-cervical extended maximal lymphadenectomy (TEMLA); supermediastinoscopies; mediastinal staging; lung cancer

Received: 03 August 2018; Accepted: 09 October 2018; Published: 09 November 2018.

doi: 10.21037 /jovs.2018.10.19

View this article at: http://dx.doi.org/10.21037/jovs.2018.10.19

For years generations had learned cervical mediastinoscopy (CM) and it's benefits for lung cancer staging, a method developed in the 1950's by Carlens (1), who proved it as a secure method tested on almost 100 patients. Nevertheless, it's only became widely used and popularized by Dr. Pearson, in Canada (2,3).

Since this time many approaches have being tested on the belief of improving accuracy on finding the occult mediastinal metastasis. Ginsberg et al. in the 1970's developed the extended mediastinoscopy (4), and more recently, with the boom of the video surgery, there were the introduction of the video mediastinoscopy (VAM) by Coosemans et al. $(5,6)$, all of them trying to make the procedure better than the long-lasting gold standard, the Carlens mediastinoscopy.

Even with this evolution, there was no gain on accuracy and negative predictive values, even with the video enhancement of visualization. Despite making the procedure easier to train young surgeons, addition of video showed similar accuracy (88-98\%) and negative predictive value (86-98\%), performing as standard CM (7).

On the last decade with the increasing interest on induction chemotherapy on lung cancer the interest of improving the $\mathrm{CM}$ numbers were on the table again, and we saw two trends; minimally invasive endoscopic procedures, as endobronchial ultrasound (EBUS) and endoscopic ultrasound (EUS), and on the other hand, more aggressive mediastinal surgeries named as supermediastinoscopies By Dr. Rami-Porta; the VAMLA and TEMLA procedures $(8,9)$. They were made possible only after the concept and development of the expandable two bladed mediastinoscope by Albert Linder and Marcel-Dahan (in cooperation with Richard-Wolf GnBh, Knittlingen, Germany) that created the possibility of an expandable surgical field and bimanual manoeuvres at the dissection. Now was possible not to only forceps biopsy the nodes, but to remove all them in bloc to examination, doing a radical lymphadenectomy and finally improving the chances of finding occult mediastinal metastasis, just like the procedure done during surgery.

The TEMLA procedure is a hybrid approach, where the initial part of the surgery is made in a standard fashion, with the assistance of a sternal elevator device and a 5 to $8 \mathrm{~cm}$ cervical incision, and where you resect chains level 1, 2, 5 and 6 and 4 right. Then, with the assistance of the Linden- 
Dahan mediastinoscope, you resect chains 7, 8, 10 right and 4 left (10). Important steps of this procedure are dissection of both recurrent nerves, carotid arteries, brachiocephalic veins, and with the exception of station 9 nodes is the most extensive technique of transcervical dissection (11).

\section{TEMLA}

The procedure was developed based on the experience and approach used for the maximal transcervical-subxiphoid

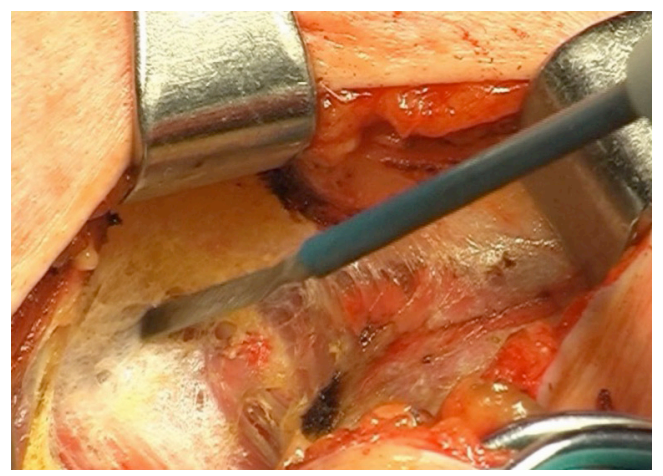

Figure 1 Cervical incision. thymectomy, developed at the same institution, with the purpose of increasing detection of mediastinal disease with the objective to offer neoadjuvant treatment for those patients stage III-A, and on a belief of, besides not proven yet, an impact on late survival (12).

Procedure starts with a 5 to $8 \mathrm{~cm}$ cervical collar incision (Figure 1), opening of the pre-thyroid muscles, and identification of right and left carotid arteries. First step then is identification and dissection of both recurrent nerves (Figure 2), and all the tissue between the carotids, since the lower poles of thyroid gland, are resected en bloc until the superior border of the innominate vein, together with the thymus upper poles with the assistance of a sternal elevator device (Figure 3) (12).

Next step is opening of the paratracheal space (Figure 4), that is done dissecting along the right vagus nerve, on the space above the artery and below the right innominate vein, until exposed the right pleura, lower aspect of inferior vena cava, and azygos vein, with the lymph nodes resected "en bloc".

After the right side, next step is the left paratracheal nodes, where you dissect along the recurrent nerve once more, with visualization improved with right traction of

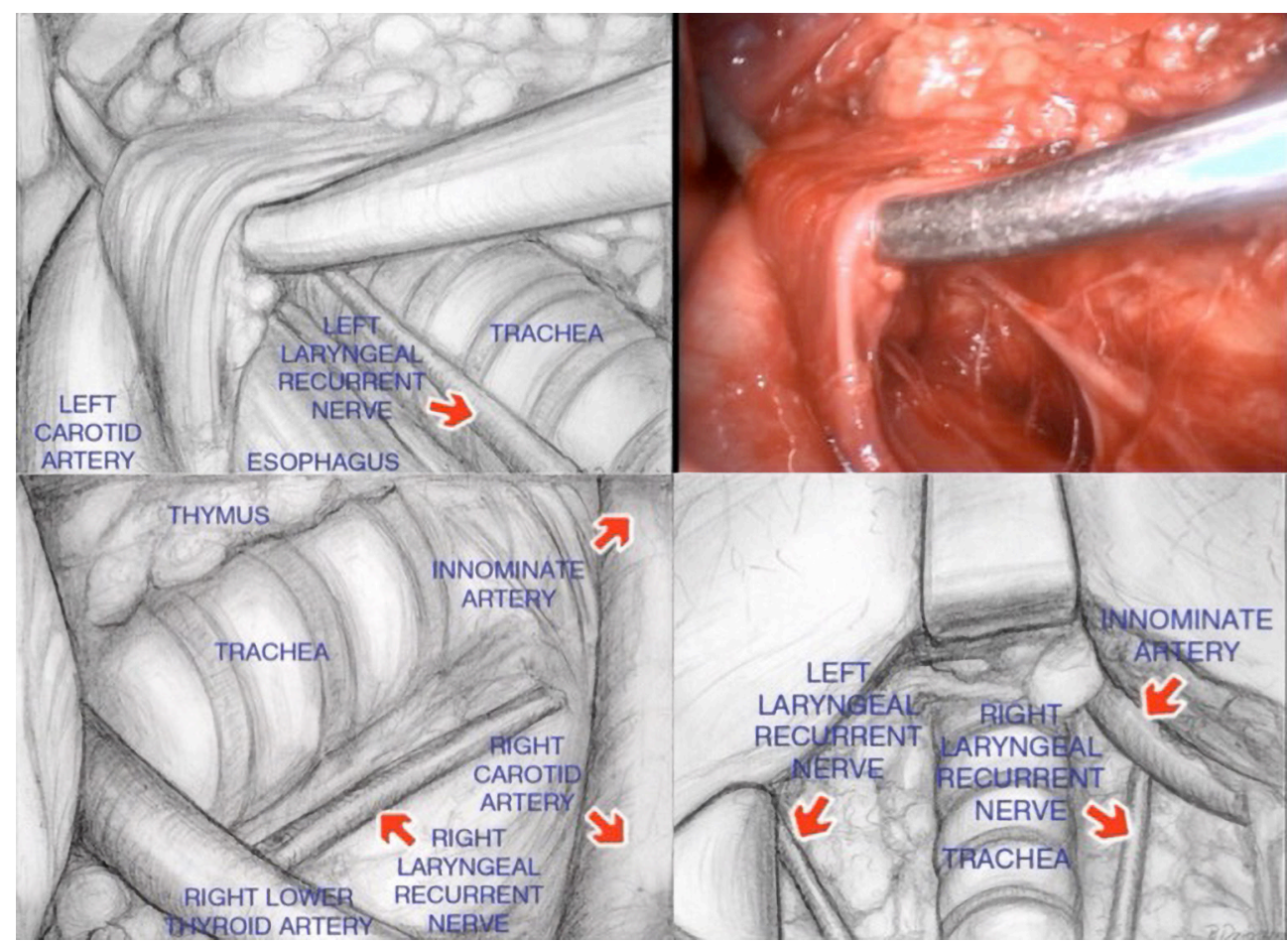

Figure 2 Dissection and exposition of recurrent nerves. 


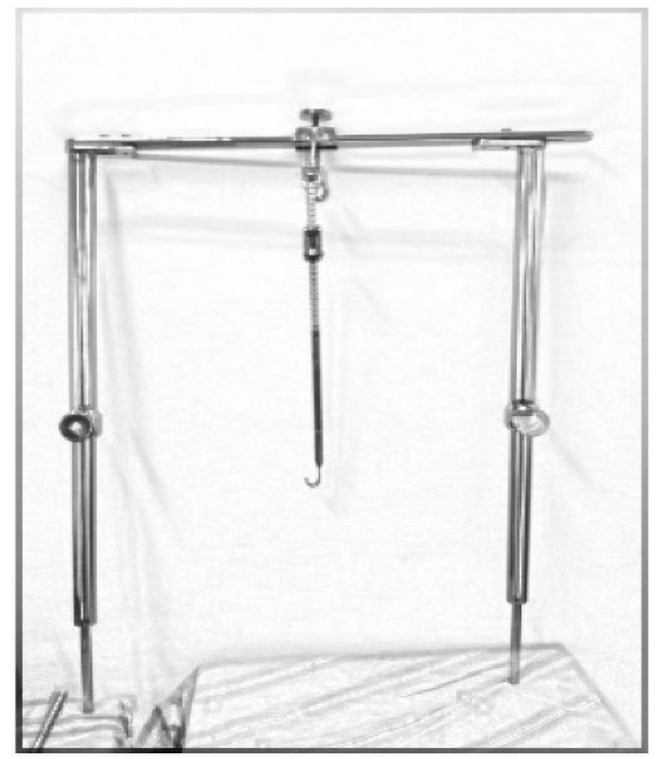

Figure 3 Sternal elevator device.

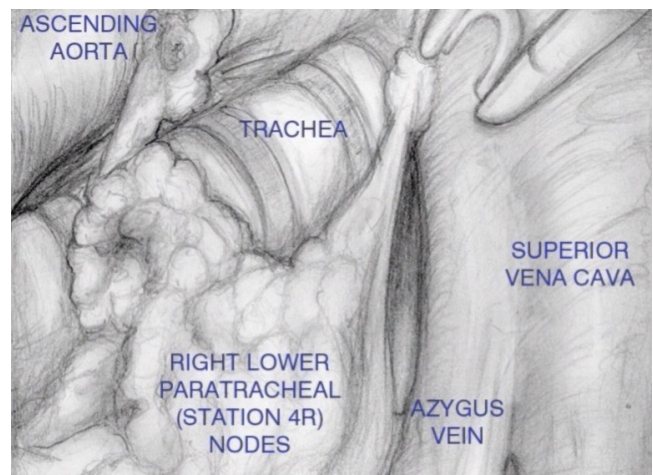

Figure 4 Paratracheal space. trachea and left and upper displacement of carotid artery, with extra care to do only blunt dissection, and retrieval of chain 2L.

Then, with the assistance of the Linden-Dahan mediastinoscope, exposure of the bronchial bifurcation is done, and opening of the fascial layer of subcarinal nodes on the lower border of the main bronchus, both sides. Dissection then goes until exposure of oesophagus, pulmonary artery and left pulmonary vein, and posterior wall of left atrium, with removal of nodes number 7 and 8 (Figure 5).

The entrance to the aorto-pulmonary window (Figure 6) and station 6 nodes lies between the left innominate vein and the left carotid artery. After retracting of the vein upwards using a long retractor, the plane is developed at the anterior surface of the aortic arch, and blunt dissection is once more done using the left vagus nerve as a landmark.

Generally, most part of TEMLA is an open procedure,

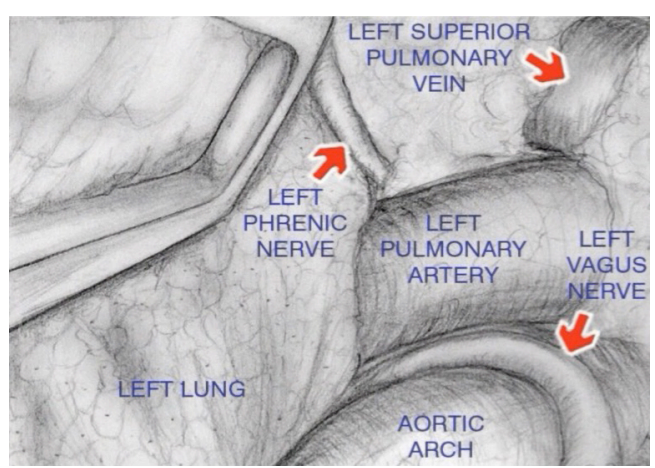

Figure 6 Aorto-pulmonary window.

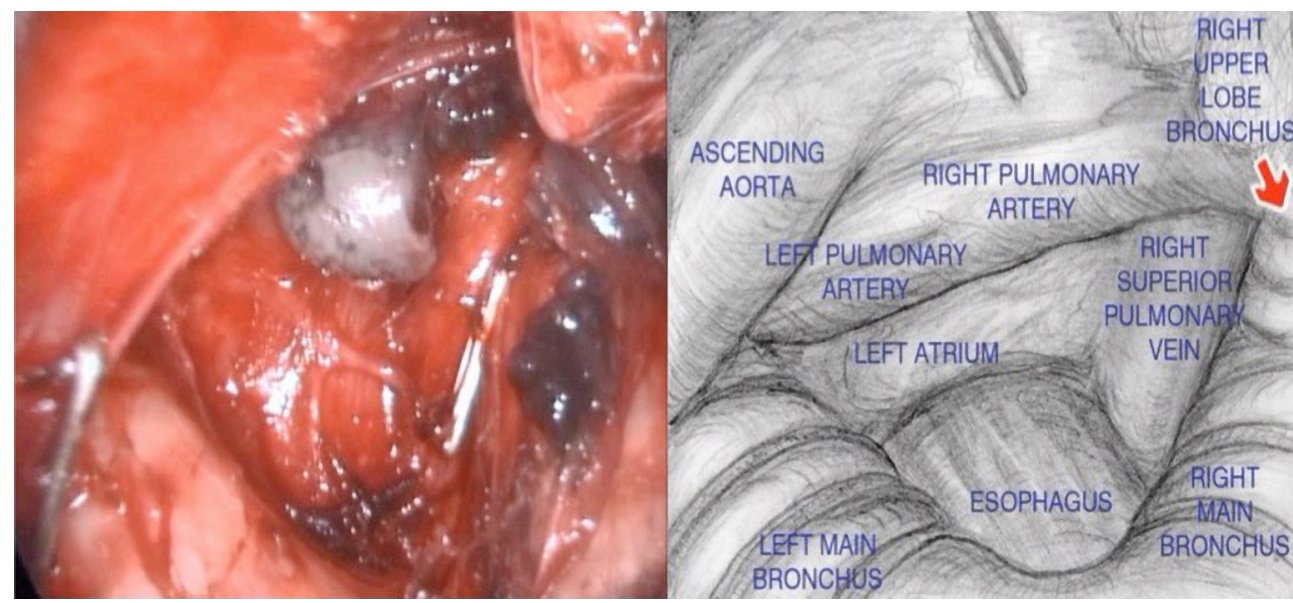

Figure 5 Subcarinal space. 
with the exception of dissection of the subcarinal (station 7), the periesophageal (station 8) nodes, and the left lower paratracheal (station 4L) nodes, which are dissected in the mediastinoscopy-assisted fashion with aid of Wolf 2-blade mediastinoscope (12).

\section{Results}

The original group staged more than 500 patients using TEMLA, with an average time of operation around 120 minutes and no intraoperative major injuries, but with five postoperative deaths reports as non-related to the procedure and overall morbidity of $7.3 \%$ (12).

Nevertheless, numbers of nodes are impressive, with an average of 38 nodes, occult N2 disease found on $21.8 \%$ of the cases and $\mathrm{N} 3$ disease on $4.3 \%$, with sensitivity of $95.6 \%$, specificity of $100 \%$ and a negative predictive value of 98.4\% (12). Unfortunately, there is no published data comparing survival of these $\mathrm{N} 2$ patients found only on TEMLA against the patients with post-operative N2 disease treated on adjuvant basis, and another concern is that $21 \%$ of patients with no $\mathrm{N} 2$ disease deteriorated clinical status and were unfit for lung resection surgery (11).

\section{VAMLA}

Despite the name of mediastinoscopy, it is as radical as TEMLA, and another lymphadenectomy technique, also developed for the maximal accuracy on staging, and was made possible by the development of the spreadable blade mediastinoscope.

Procedure starts with a cervical transverse incision and dissection until the pre-tracheal fascia, as a standard mediastinoscopy. Them, first tracheal bifurcation is exposed, as is superior aspect of pulmonary artery, creating the space were the scope should enter and open the blades.

Dissection progress along the medial borders of both bronchi and exposing oesophagus inferiorly, with resection of all subcarinal nodes, just as made in TEMLA (Figure 5).

Then, the mediastinoscope is retracted to the innominate artery and after opening the thin layer of fascia, the pleura parietalis and inferior aspect of vena cava superior are exposed, and the pre- and right paratracheal fat pads are removed en bloc down to the azygos vein and the right main bronchus.

Finally, the left recurrent nerve is visualized by transparency, and the pre-tracheal fascia is divided between the nerve and the left border of the airway. The left paratracheal and tracheobronchial adipose tissue is carefully dissected, and all visible lymph nodes removed.

\section{Results}

VAMLA also showed to be a full lymphadenectomy procedure, with high average nodes harvested per procedure (20.7 nodes), with completeness of resection ranging from $94 \%$ to $100 \%$ and a shorter procedure time (54 minutes) and lower complication rates $(4.6 \%$ as compared to TEMLA. Occult N2 disease was found on $13 \%$ of the patients, with a sensitivity on $93.8 \%$ and specificity of $100 \%$, and a false negative rate of only $0.9 \%(5,12)$.

\section{When to use them}

Both TEMLA and VAMLA can provide higher levels of accuracy on lung cancer staging, making almost zero the chance of an occult mediastinal nodal disease, and should be used whenever there are questions concerning mediastinal status that can change treatment course, especially on neoadjuvant enthusiast services.

There is a wide range of individual and institutional preferences regarding multimodal treatment of stage III disease, that can guide the surgical team to the optimal procedure based on how eager are they on finding occult N2 disease before surgery.

On our service we reserve these approaches basically to these cases:

* Improving mediastinal staging and detection of occult N2 disease, selecting candidates for neoadjuvant chemotherapy on those CT and pet negative nodes specially on those $\mathrm{N} 1$ positive cases, also working as a pre-resectional lymphadenectomy for VATS;

* Reduce radiation fields on patient's compromised or non-resectable cases;

* Improve radical staging on certain settingssynchronic disease, oligometastatic disease, left side tumors;

* Positive PET end/or CT nodes, that CM and frozen sections failed to confirm disease.

Nevertheless, we do not recommend either of the techniques as the first step on mediastinal invasive staging, especially if there is either CT or PET positive nodes, where fine needle approach can have excellent results, making possible to use the cervical lymphadenectomies as a re-staging procedure. 


\section{Conclusions}

Both TEMLA and VAMLA are invasive radical procedures, performed under general anaesthesia, and with morbidities that should be considered when proposing their use. Also, there is a need of trained team, specific equipment and desirable a patient selection protocol, as it should not be the primary method of investigation, or used just as a confirmation of a clinical positive mediastinal node.

In both cases, laryngeal nerve compromise is the main concern, and even it can be sometime temporary, have deleterious effect mainly on lung resection surgery recovery. Also, we would like to address that the result numbers are in centers of excellence using this approaches, and high experience on transcervical dissections, and extra caution should be taken by lower volume centers.

On our point of view, the most promising option is the use of EUS procedures for initial staging, learning the transcervical lymphadenectomies as a second step, assuring node-negative mediastinum prior to lung resection surgery.

\section{Acknowledgments}

The authors would like to thank Dr. Marcin Zielinski, MD, from the Department of Thoracic Surgery, Pulmonary Hospital, Zakopane, Poland, from whom we learned the principles of transcervical mediastinal lymphadenectomy and maximal thymectomy, and also for kindly attend to our request for using his images.

Funding: None.

\section{Footnote}

Provenance and Peer Review: This article was commissioned by the Guest Editors (Ricardo M. Terra and Paula A. Ugalde) for the series "Minimally Invasive Surgery Robotics and VATS in Brazil" published in Fournal of Visualized Surgery. The article has undergone external peer review.

Conflicts of Interest: All authors have completed the ICMJE uniform disclosure form (available at http://dx.doi. org/10.21037/jovs.2018.10.19). The series "Minimally Invasive Surgery - Robotics and VATS in Brazil" was commissioned by the editorial office without any funding or sponsorship. The authors have no other conflicts of interest to declare.
Ethical Statement: The authors are accountable for all aspects of the work in ensuring that questions related to the accuracy or integrity of any part of the work are appropriately investigated and resolved. All procedures performed in studies involving human participants were in accordance with the ethical standards of the institutional and/or national research committee(s) and with the Helsinki Declaration (as revised in 2013). Written informed consent was obtained from the patient for publication of this manuscript and any accompanying images.

Open Access Statement: This is an Open Access article distributed in accordance with the Creative Commons Attribution-NonCommercial-NoDerivs 4.0 International License (CC BY-NC-ND 4.0), which permits the noncommercial replication and distribution of the article with the strict proviso that no changes or edits are made and the original work is properly cited (including links to both the formal publication through the relevant DOI and the license). See: https://creativecommons.org/licenses/by-nc-nd/4.0/.

\section{References}

1. Carlens E. Mediastinoscopy: a method for inspection and tissue biopsy in the superior mediastinum. Dis Chest 1959;36:343-52.

2. Pearson FG. Mediastinoscopy: a method of biopsy in the superior mediastinum. Can J Surg 1963;6:423-9.

3. Pearson FG. Lung cancer. The past twenty-five years. Chest 1986;89:200S-205S.

4. Ginsberg RJ, Rice TW, Goldberg M, et al. Extended cervical mediastinoscopy. A single staging procedure for bronchogenic carcinoma of the left upper lobe. J Thorac Cardiovasc Surg 1987;94:673-8.

5. Call S, Obiols C, Rami-Porta R, et al. Video-Assisted Mediastinoscopic Lymphadenectomy for Staging Non-Small Cell Lung Cancer. Ann Thorac Surg 2016;101:1326-33.

6. Coosemans W, Lerut TE, Van Raemdonck DE. Thoracoscopic surgery: the Belgian experience. Ann Thorac Surg 1993;56:721-30.

7. Zakkar M, Tan C, Hunt I. Is video mediastinoscopy a safer and more effective procedure than conventional mediastinoscopy?. Interact Cardiovasc Thorac Surg 2012;14:81-4.

8. Rami-Porta R. Supermediastinoscopies: A Step Forward in Lung Cancer Staging. J Thorac Oncol 2007;2:355-6. 
9. Herth F, Becker HD, Manegold C, et al. Endobronchial ultrasound (EBUS)--assessment of a new diagnostic tool in bronchoscopy for staging of lung cancer. Onkologie 2001;24:151-4.

10. Zielinski M, Kuzdzal J, Nabialek T, et al. Transcervical extended mediastinal lymphadenectomy. Multimed Man

doi: $10.21037 /$ jovs.2018.10.19

Cite this article as: Melo IA, Fortunato G, Pereira ST. Supermediastinoscopies: where to fit and how to do on cancer practice. J Vis Surg 2018;4:234.
Cardiothorac Surg 2006;2006:mmcts.2005.001693.

11. Kużdżał J, Warmus J, Grochowski Z. Optimal mediastinal staging in non-small cell lung cancer: what is the role of TEMLA and VAMLA? Lung Cancer 2014;86:1-4.

12. Zieliński M. Transcervical extended mediastinal lymphadenectomy. Thorac Surg Clin 2010;20:215-23. 